\title{
Regulation of glucose homeostasis in rat jejunum by despentapeptide-insulin in vitro
}

\author{
N WOLLEN AND G L KELLETT \\ From the Department of Biology, University of York, York
}

\begin{abstract}
SUMmaRY The regulation of the absorption and metabolism of glucose in rat small intestine by insulin was studied by the perfusion of isolated loops of proximal jejunum in vitro. The addition of an active, monomeric form of insulin, despentapeptide-insulin, to the serosal side of the intestine from normal rats inhibited luminal glucose absorption (421 (11) to 285 (11) $\mu \mathrm{mol} / \mathrm{h} / \mathrm{g} \mathrm{dry} \mathrm{wt,} \mathrm{p<0.001)}$ and lactate production (340 (28) to $192(26) \mu \mathrm{mol} / \mathrm{h} / \mathrm{g}$ dry wt, $\mathbf{p}<0.001$ ), but had no effect on glucose utilisation ( 231 (11) and $210(16) \mu \mathrm{mol} / \mathrm{h} / \mathrm{g} \mathrm{dry} \mathrm{wt).} \mathrm{The} \mathrm{production} \mathrm{of} \mathrm{acute} \mathrm{insulin} \mathrm{deficiency} \mathrm{by} \mathrm{the}$ injection of anti-insulin serum in vivo caused a marked inhibition of luminal glucose absorption (421 (11) to 240 (13) $\mu \mathrm{mol} / \mathrm{h} / \mathrm{g}$ dry wt, $p<0 \cdot 001)$, glucose utilisation (231 (11) to 48 (2) $\mu \mathrm{mol} / \mathrm{h} / \mathrm{g}$ dry wt, $\mathrm{p}<0.001$ ) and lactate production (340 (28) to $94(2) \mu \mathrm{mol} / \mathrm{h} / \mathrm{g}$ dry wt, $\mathbf{p}<0.001)$ in vitro. The effects of insulin deficiency were reversed by despentapeptide-insulin in vitro, so that the rates of absorption and metabolism for intestine from insulin deficient and normal rats were similar in the presence of the modified insulin. All the effects caused by insulin deficiency and despentapetide-insulin were apparent within minutes and could not be attributed to hyperglycaemia. It is concluded that rat small intestine is subject to rapid and direct regulation by insulin.
\end{abstract}

Glucose crosses the rat small intestine by two routes; after absorption across the brush border membrane, it is either transported across the basolateral membrane unchanged or it is metabolised to lactate for subsequent hepatic gluconeogenesis. '2 The importance of each of these routes is shown by the fact that of the absorbed glucose, some $25-45 \%$ is transported unchanged from the lumen into the vasculature, while $55-75 \%$ is metabolised with about $80 \%$ of that converted to lactate..$^{3-6}$ In experimental diabetes, the percentage of glucose transported unchanged is enhanced in two ways: directly, by an increase in the synthesis of glucose carriers in the basolateral membrane $^{7}$ and, indirectly, by a diminution in glucose metabolism. ${ }^{\circ 8}$ In diabetes therefore, the balance between transport and metabolism is shifted markedly in favour of the former and is one factor contributing to abnormal fluctuations in blood glucose concentrations, especially in the postprandial state.

Address for correspondence: Dr G L. Kellett. Department of Biology. University of York. York YO1 5DD

Received for publication 14 March 1988
The stimuli responsible for the enhanced transport observed in diabetes have been a matter of debate for some years. ${ }^{411}$ Experiments in which insulin reversed the effects of diabetes when injected in vivo, while failing to do so when added to intestinal preparations in vitro, ${ }^{12-17}$ have, however, led to the view that intestine is an insulin insensitive tissue and that the changes induced by diabetes arise as a secondary consequence of insulin deficiency through the effects of the ensuing hyperglycaemia. Indeed, when normal rats are maintained in a hyperglycaemic state by intravenous glucose infusion, the synthesis of glucose carriers in the basolateral membrane, and hence transport, is enhanced within four hours.'

In studies designed to explain the diminution of glucose metabolism that occurs in streptozotocin diabetic rats, ${ }^{\circ}$ we observed that mucosal phosphofructokinase was inhibited when compared with normal rats. The fact that inhibition was not caused by hyperglycaemia, and could be reversed by administration of insulin for 24 hours, suggested that insulin deficiency might be responsible. ${ }^{1 \times 19}$ Further support for this view was provided by the observa- 
tion that the production of insulin deficiency in rats by the injection of anti-insulin serum resulted in a large increase in the percentage of glucose transported unchanged from the lumen to the vasculature and also in a large decrease in glucose metabolism caused by phosphofructokinase inhibition. ${ }^{6}$ All the changes produced by insulin deficiency occurred within two minutes, when plasma glucose concentrations were unchanged, and were completely reversed within two minutes when antiserum was neutralised by the injection of insulin in vivo. Furthermore, changes in the rate of lactate production in response to acute changes in insulin levels in vivo correlated with changes in the proportion of the insulin sensitive enzyme pyruvate dehydrogenase present in its active form in mucosa. These observations, and the rapidity of the observed changes, suggested that the regulation of intestinal function by insulin was direct through receptors on the enterocyte surface. This conclusion is confirmed here in a demonstration of the regulation of glucose absorption, transmural transport and metabolism in vitro by despentapeptide-insulin, an active, monomeric form of insulin."1"

\section{Methods}

RATS

Female Wistar rats $(220-250 \mathrm{~g})$ were fed ad libitum on standard laboratory diet (Oxoid modified 41B) with free access to water. Antiserum to bovine insulin was raised in guinea pigs ${ }^{21}$ and had a neutralising capacity of approximately $4 \mathrm{U} / \mathrm{ml}$ as determined by immunochemical titration. Insulin deficiency was produced in anaesthetised rats (Sagatal, $0 \cdot 1 \mathrm{ml} / 100 \mathrm{~g}$ body wt) by injection of the femoral vein with $1 \mathrm{ml}$ anti-insulin serum, which was the volume required to produce maximal plasma glucose concentrations (approx 20 $\mathrm{mM}$ ) after 60) minutes: control rats received $1 \mathrm{ml}$ of $0.9 \% \mathrm{NaCl}$.

Glucose absorption, transmural transport and metabolism were studied in isolated jejunal loops in vitro using the preparation described by Fisher and Parsons:2 modified so that recirculated luminal perfusate was segmented with bubbles of gas $\left(\mathrm{O}_{2} / \mathrm{CO}_{2}\right.$, $19: 1) ;{ }^{32+}$ the flow rates of perfusate and gas were 25 $\mathrm{ml} / \mathrm{min}$ and $3 \mathrm{ml} / \mathrm{min}$ respectively and the loops of jejunum were $20 \mathrm{~cm}$ in length starting at a point $5 \mathrm{~cm}$ below the ligament of Treitz. Jejunum was perfused for one hour, beginning 10 minutes after the injection of either anti-insulin serum or saline, with a medium consisting of Krebs-Henseleit buffer containing glucose $(5 \mathrm{mmol} / \mathrm{l})$ : the serosal side of the loop was bathed in the same medium. In experiments designed to reverse the effects of anti-insulin serum, despentapeptide-insulin was added at the indicated concentrations to the serosal medium. In this preparation, glucose is absorbed from the luminal perfusate by the mucosa; part of the absorbed glucose is then utilised by the tissue and the remainder is transported across the basolateral membrane into the serosal medium. Absorption was therefore measured by the rate of disappearance of glucose from the luminal perfusate, transmural transport by its rate of appearance in the serosal medium and utilisation by their difference under the steady state conditions which pertained between five and 60 minutes perfusion. Steady states were achieved within five minutes with intestine from either normal or insulin deficient rats irrespective of whether despentapeptide-insulin was present. Lactate appeared predominantly in the serosal medium, but also to a small extent in the luminal perfusate. Total lactate production was therefore given by the sum of the rates of appearance in both compartments. The conversion of glucose to lactate was given by $(0 \cdot 5 \times$

Table 1 The regulation of glucose absorption, transmural transport and metabolism in rat small intestine by despentapeptide-insulin in vitro

\begin{tabular}{|c|c|c|c|c|c|c|c|c|}
\hline \multirow[b]{3}{*}{$\begin{array}{l}\text { Treatment of } \\
\text { rat }\end{array}$} & \multirow[b]{3}{*}{$n$} & \multirow[b]{3}{*}{$\begin{array}{l}\text { Despentapeptide- } \\
\text { insulin } \\
\text { (umol/l) }\end{array}$} & \multicolumn{4}{|c|}{ Rate ( $\mu \mathrm{mol} / \mathrm{h} / \mathrm{g} d r y w t)$} & \multirow[b]{3}{*}{$\begin{array}{l}\text { Transmural } \\
\text { transport/ } \\
\text { absorption (\%) }\end{array}$} & \multirow[b]{3}{*}{$\begin{array}{l}\text { Glucose utilised } \\
\text { converted into } \\
\text { lactate }(\%)\end{array}$} \\
\hline & & & \multicolumn{3}{|l|}{ Glucose } & \multirow{2}{*}{$\begin{array}{l}\text { Lactate } \\
\begin{array}{l}\text { Total } \\
\text { production }\end{array}\end{array}$} & & \\
\hline & & & Absorption & $\begin{array}{l}\text { Transmural } \\
\text { transport }\end{array}$ & Utilisation & & & \\
\hline $0.9 \% \mathrm{NaCl}$ (control) & 8 & - & $421(11)$ & $190(8)$ & $231(11)$ & $341)(28)$ & $45(2)$ & $72(3)$ \\
\hline $0.9 \% \mathrm{NaCl}$ & 4 & 10 & $285(11)^{*}$ & $75(12)^{*}$ & $210(16)$ & $192(26) \div$ & $26(4)^{*}$ & $46(5)^{*}$ \\
\hline Anti-insulin serum & 6 & - & $240(13)^{*}$ & $193(13)$ & $48(2)^{*}$ & $94(2)^{*}$ & $80(1)^{*}$ & $97(3)^{*}$ \\
\hline Anti-insulin serum & 5 & 1 & $221(38)^{*}$ & $77(31) \dagger$ & $144(10)^{*}$ & $154(12)^{*}$ & $29(9) \ddagger$ & $54(6) \ddagger$ \\
\hline Anti-insulin serum & 5 & 10 & $284(11)^{*}$ & $91(26) \div$ & $193(20)$ & $146(22)^{*}$ & $30)(8) \div$ & $37(2)^{*}$ \\
\hline
\end{tabular}

All experimental details are given in the Methods section. When present, despentapeptide-insulin was added to the serosal medium. Values are given as means $(\mathrm{SE})$. p values are given for the comparison of experimental and normal control perfusions: ${ }^{*} p<() \cdot(0) 1:{ }^{\dagger} p<() \cdot() 1 ;$ $\$ p<0 \cdot(1) 5$. 
total lactate production) expressed as a percentage of the rate of glucose utilisation. Rates are expressed in $\mu \mathrm{mol} / \mathrm{h} / \mathrm{g}$ dry wt. Glucose and lactate were determined as described. ${ }^{25}$ Values are expressed as means (SE).

Mucosal samples for enzyme assay were collected with a microscope slide from jejunum removed from rats 10 minutes after the injection of anti-insulin serum or saline. ${ }^{1 \times}$ The samples were then frozen in liquid nitrogen and were subsequently homogenised directly without being thawed. Mucosal extracts for the determination of phosphofructokinase activity were prepared and then assayed at $\mathrm{pH} 7 \cdot 0$, where the enzyme displays regulatory properties. ${ }^{1 \times}$ These were expressed as the activity ratio, $\mathrm{v}_{0.5} / \mathrm{V}$, where $\mathrm{v}_{0.5}$ is the activity in the presence of fructose 6-phosphate $(0.5 \mathrm{mmol} / \mathrm{l})$ and ATP $(2.5 \mathrm{mmol} / \mathrm{l})$ at $\mathrm{pH} 7.0$ and $\mathrm{V}$ is the maximal activity at $\mathrm{pH} \mathrm{8.0.} \mathrm{A} \mathrm{decrease} \mathrm{in} \mathrm{v}_{0.5} / \mathrm{V}$ reflects an increase in the susceptibility of the enzyme to inhibition by ATP. Mucosal extracts were also prepared for the determination of pyruvate dehydrogenase activity. ${ }^{26}$ This enzyme exists in an active and an inactive form and the conversion of the inactive to the active form is stimulated by insulin. Incubation of extracts with $\mathrm{Mg}^{++}$converts the inactive to the active form and so it is normal practice to determine the proportion of the enzyme in the active form by assay in the absence (initial activity) and presence (final activity) of $\mathrm{Mg}^{++}$. We were able to determine only the initial activity, however, because the intestinal enzyme is irreversibly inactivated during incubation with $\mathrm{Mg}^{++} .{ }^{27}$

Despentapeptide-insulin was given by Mrs S Tolly and Professor G G Dodson (Chemistry Department, University of York). Biochemicals were purchased from Sigma Chemical Co and other reagents were of analytical grade.

\section{Results}

When jejunal loops from normal, fed rats injected with $0.9 \% \mathrm{NaCl}$ were perfused in a modified Fisher and Parsons preparation ${ }^{22-24}$ with glucose present on both sides at a concentration of $5 \mathrm{mmol} / \mathrm{l}$ (normal control), $45 \%$ of the glucose absorbed from the lumen was transported unchanged into the serosal medium: the rest was metabolised with $74 \%$ conversion to lactate and $26 \%$ assumed to be oxidised (Table 1). When despentapeptide-insulin was present in the serosal medium at a concentration of $10 \mu \mathrm{mol} / \mathrm{l}$, glucose utilisation remained the same because the activity of phosphofrustokinase was unaffected, whereas total lactate production was diminished to $57 \%$ of normal because of the increase in the proportion of pyruvate dehydrogenase in its active form (Tables 1 and 2). The absorption and transmural transport of glucose were diminished to $68 \%$ and $40 \%$ of normal respectively.

The activities of phosphofructokinase and pyruvate dehydrogenase in the mucosa of rats made deficient in insulin by the injection of anti-insulin serum were both markedly inhibited compared with normal (Table 2), so that glucose utilisation and lactate production were diminished to $21 \%$ and $28 \%$ of normal, while at the same time the percentage of glucose converted to lactate was increased from $72 \%$ to $97 \%$ (Table 1). The absorption of glucose was also inhibited, being diminished to $58 \%$ of control values. Because utilisation was diminished to an even greater extent, to $21 \%$ of control values, however, transmural transport expressed as a percentage of absorption was increased from $45 \%$ to $80 \%$. The diminution in glucose utilisation caused by the anti-insulin serum was only partially reversed by despentapeptideinsulin when present at a concentration of $1 \mu \mathrm{mol} / \mathrm{l}$ in the serosal medium, presumably because of the need to penetrate the ruptured vasculature and to neutralise the residual antiserum (Table 1). The concentration of despentapeptide-insulin was therefore increased to $10 \mu \mathrm{mol} / \mathrm{l}$, when glucose utilisation and phosphofructokinase activity were returned towards normal values and were no longer significantly differ-

Table 2 The regulation of mucosal phosphofructokinase and pyruvate dehydrogenase by despentapeptide-insulin in vitro

\begin{tabular}{llll}
\hline & $\begin{array}{l}\text { Despentapeptide-insulin } \\
\text { Treatment of rat }\end{array}$ & $\begin{array}{l}\text { Phosphofructokinase } \\
v_{0.5} / V\end{array}$ & $\begin{array}{l}\text { Pyruvate dehydrogenase } \\
\text { (initial activity, } \\
\text { nmol/min/g wet wt) }\end{array}$ \\
\hline $0.9 \% \mathrm{NaCl}(\mathrm{control})$ & - & $0 \cdot 47(0.01)[7]$ & $237(18)[8]$ \\
$0.9 \% \mathrm{NaCl}$ & 10 & $0 \cdot 49(0 \cdot(04)[3]$ & $381(26)[3]^{+}$ \\
Anti-insulin serum & - & $0 \cdot 24(0 \cdot 04)[6]^{*}$ & $138(9)[6]^{*}$ \\
Anti-insulin serum & 10 & $0 \cdot 47(0 \cdot(2)[3]$ & $261(40)[3]$ \\
\hline
\end{tabular}

Perfusions were performed for 10 minutes as described in the Methods section. The activity ratio $v_{0.5} / \mathrm{V}$. of phosphofructokinase was measured at $\mathrm{pH} 7.0$ in the presence of fructose 6-phosphate $(0.5 \mathrm{mmol} / \mathrm{l})$ and ATP $(2.5 \mathrm{mmol} / \mathrm{l})$ and reflects changes in the regulatory properties of the enzyme ${ }^{19}$ The initial activity of pyruvate dehydrogenase, reflecting the proportion of the enzyme in its active form, was determined as described previously. ${ }^{2}{ }^{26}$ Values are given as means (SE) for the numbers of rats in square brackets. p values are given the comparison of experimental and control perfusions: ${ }^{*} p<0 \cdot 001:{ }^{\dagger} p<0 \cdot 01$. 
ent from those for normal intestine either alone or in the presence of despentapeptide-insulin (Tables 1 and 2). The rates of absorption and transmural transport of glucose remained significantly diminished compared with those for normal intestine, but were not significantly different from those for normal intestine in the presence of despentapeptide-insulin. Lactate production responded in a similar way.

While pyruvate dehydrogenase activity in intestine from rats treated with anti-insulin serum was enhanced by despentapeptide-insulin, however, it was not significantly different from that measured for normal intestine alone (Table 2 ) and was significantly less than that measured for normal intestine in the presence of the modified insulin $(p<0 \cdot 05)$. Whenever despentapeptide-insulin was present in the serosal medium, the percentage of glucose converted to lactate was far lower than observed for intestine from either normal or anti-insulin serum treated rats (Table 1).

\section{Discussion}

Our experiments show that despentapeptide-insulin is able to overcome the effects of insulin deficiency on glucose utilisation and lactate production and on the activities of phosphofructokinase and pyruvate dehydrogenase in rat jejunum in vitro. We have previously shown by crossover measurements of glycolytic metabolites with small intestine from normal and insulin deficient rats that phosphofructokinase is the rate limiting enzyme of glycolysis. ${ }^{6}$ Accordingly the effect of despentapeptide-insulin on metabolism appears relatively straightforward in that it does not affect phosphofructokinase activity and glucose utilisation in intestine from normal rats, but reverses the inhibition of phosphofructokinase activity and hence of glucose utilisation observed in the intestine of insulin deficient rats, so that normal values are almost completely restored (Tables 1 and 2). Similarly the changes in lactate production and in the percentage of glucose converted to lactate are, in general, accounted for by changes in the proportion of pyruvate dehydrogenase present in the active form in mucosa, coupled, of course, with changes in glucose utilisation.

The inhibition of glucose absorption by anti-insulin serum was not overcome by despentapeptide-insulin. Absorption in intestine from insulin-deficient and from normal rats was the same in the presence of despentapeptide-insulin $(10 \mu \mathrm{mol} / \mathrm{l})$, however, because the modified insulin inhibited absorption in normal intestine (Table 1). It is of interest to note that we have previously observed comparable behaviour in vivo as opposed to in vitro, for the injection of native insulin into rats before subsequent perfusion of jejunum in vitro also resulted in inhibition of absorption. " One interpretation of this behaviour is that the response of intestinal absorption to insulin is biphasic, being stimulatory at physiological concentrations that are neutralised by anti-insulin serum and inhibitory at higher concentrations. As a consequence of the changes in absorption and metabolism produced by anti-insulin serum and/ or despentapeptide-insulin, transmural transport is not significantly different in intestine from either normal or insulin deficient rats in the presence of the modified insulin.

It is to be emphasised that hyperglycaemia, which is known to enhance intestinal glucose transport, ' is not a factor in any of the experiments for the intestine was removed 10 minutes after the injection of antiinsulin-serum, when plasma glucose concentrations were not significantly different from normal, ${ }^{\circ}$ and in the perfusion experiments the concentration of glucose was fixed at $5 \mathrm{mmol} / \mathrm{l}$.

Although there have been numerous studies on the effects of diabetes on glucose absorption, transmural transport and metabolism by rat small intestine, their regulation by insulin has not been shown previously. We suggest that there are several reasons for this: (1) In streptozotocin diabetes, transmural transport is enhanced directly by an increase in the synthesis of glucose carriers in the basolateral membrane in response to hyperglycaemia for a period of at least four hours. ' Transmural transport is also enhanced indirectly by a diminution in glucose utilisation mediated by the inhibition of phosphofructokinase in response to insulin deficiency (Table 2 ). The inhibition of phosphofructokinase is reinforced in streptozotocin-diabetic rats through a diminution in enzyme concentration caused by changes in protein synthesis that can only be reversed by insulin administration over 24 hours. ${ }^{19}$ The changes in protein synthesis that affect transmural transport directly and indirectly in chronic diabetes cannot be reversed by short term experiments with insulin in vitro.

(2) Native insulin is a hexamer composed of subunits each of $\mathrm{M}_{\mathrm{r}}$ approx. 6000; the hexamer is therefore too large to enter the ruptured vasculature of the Fisher and Parsons $\mathrm{s}^{22}$ preparation (data not shown) and of the commonly used intestinal preparations such as rings and everted sacs. ${ }^{13-17}$ It was this fact that dictated the use of despentapeptide-insulin. This form of insulin is synthesised by the removal of five residues from the C-terminal of the $\mathrm{B}$ chain that are essential for association of the hexamer. ${ }^{21}$ Despentapeptide-insulin is therefore entirely monometic $\left(\mathrm{M}_{\mathrm{r}}\right.$ approx. 5000) and is just able to enter the ruptured vasculature. It has approximately $40 \%$ of the activity of native insulin and is thus equally 
effective at $2 \cdot 5$-fold concentrations. The concentrations of despentapeptide-insulin used in the present studies are high because the need to penetrate the ruptured vasculature and to overcome the residual antiserum when present. In order to study the regulation of intestine at physiological concentrations in vitro, it will be necessary to use a vascularly perfused preparation. Regulation of intestine at physiological insulin concentrations in vivo has already been shown for the changes produced by the injection of anti-insulin serum into normal rats reflect, of course, a change in circulating insulin concentrations from normal, physiological values to zero. ${ }^{6}$ The fact that despentapeptide-insulin was effective when added to the serosal medium is consistent with the view that enterocytes possess receptors for insulin and that these are located in the basolateral membrane of the epithelial cell. ${ }^{2 \times-34}$

(3) Simple intestinal preparations (rings and everted sacs) are inadequately oxygenated. Hence the concentrations of effectors in vivo are such that the activity of phosphofructokinase is unrestrained and these preparations do not display a Pasteur effect. ${ }^{35-37}$ As a consequence, changes in the susceptibility of phosphofructokinase to different effectors in response to acute changes in insulin concentration will not be manifested as changes in the rate of glucose utilisation, nor, therefore, as changes in absorption and transmural transport. In contrast, the modified Fisher and Parsons ${ }^{22}$ preparation used in our studies is highly oxygenated, so that changes in the regulatory properties of phosphofructokinase are reflected in changes in utilisation. ${ }^{6}$ At the same time, the Fisher and Parsons preparation has the advantage that it is much less complex than one that is vascularly perfused.

This work was supported by the British Diabetic Association. NW was the recipient of a Medical Research Council Studentship.

\section{References}

1 Remesy C, Demigne C, Autrene J. Interorgan relationships between glucose, lactate and amino acids in rats fed on high carbohydrate or high protein diet. Biochem J 1978; 170: 321-9.

2 Shapiro A, Shapiro B. Role of the liver in intestinal glucose absorption. Biochim Biophys Acta 1979; 586: 123-7.

3 Hanson PJ, Parsons DS. Glutamine and glucose as fuels for the fed, fasted and acidotic rat small intestine. J Physiol (Lond) 1977; 166: 509-19.

4 Pritchard PJ, Porteous JW. Steady state metabolism and transport of D-glucose by rat small intestine in vitro. Biochem J 1977; 164; 1-14.

5 Nicholls TJ, Leese HJ, Bronk JR. Transport and metabolism of glucose by rat small intestine. Biochem $J$ 1983; 212: 183-7.

6 Kellett GL, Jamal A, Robertson JP. Wollen N. The acute regulation of glucose absorption, transport and metabolism in rat small intestine by insulin in vivo. Biochem J 1983; 219: 1027-35.

7 Czaky TZ, Fisher E. Intestinal sugar transport in experimental diabetes. Diabetes 1981; 30: 568-74.

8 Hanson PJ, Parsons DS. Factors affecting the utilisation of ketone bodies and other substrates by rat jejunum: effects of fasting and diabetes. J Physiol (Lond) 1978; 278: $55-67$.

9 Levin RJ. The effect of hormones on the absorptive, metabolic and digestive functions of the small intestine. J Endocrinol 1969; 45: 315-48.

10 Caspary WF. The effect of insulin and diabetes melitus on the digestive - absorptive function of the small intestine. Digestion 1973; 9: 248-63.

11 Karasov WH, Diamond JM. Adaptive regulation of sugar and amino acid transport by vertebrate intestine. Am J Physiol 1983; 245: G445-62.

12 Aulsenbrook KA. Intestinal transport of glucose and sodium: changes in alloxan diabetes and effects of insulin. Experimentia 1965; 21 : 346-7.

13 Crane RK. Effect of alloxan diabetes on the active transport of sugars by rat small intestine in vitro. Biochem Biophys Res Commun 1961; 4: 436-40.

14 Fromm D, Field M, Silen W. Effect of insulin on sugar and amino acid transport across isolated small intestine. Am J Physiol 1969; 217: 53-7.

15 Olson WA, Rosenberg I. Intestinal transport of sugars and amino acids in diabetic rats. J Clin Invest 1970; 49: 96-105.

16 Lesse HJ, Mansford KRL. Effect of insulin deficiency on the transport of glucose by rat small intestine. FEBS Lett 1969; 2: 193-4.

17 Lesse HJ, Mansford KRL. The effect of insulin deficiency on the transport and metabolism of glucose by rat small intestine. J Physiol 1971; 212: 819-38.

18 Jamal A, Kellett GL. The effect of starvation on the control of phosphof ructokinase activity in the epithelial cells of the rat small intestine. Biochem J 1983; 210: 129-35.

19 Jamal A, Kellett GL. Regulation of mucosal phosphofructokinase in the small intestine of the streptozotocindiabetic rat. Diabetologia 1983; 25: 355-9.

$20 \mathrm{Ru}-$ Chang B, Cutfield SM, Dodson EJ, et al. Molecular replacement studies on crystal forms of despentapeptide-insulin. Acta Cryst 1983; B39: 90-8.

21 Neubauer HP, Schone HH. The immunogenicity of different insulins in several different animal species. Diabetes 1978; 27: 8-15.

22 Fisher RB, Parsons DS. A preparation of surviving rat small intestine for the study of absorption. J Physiol (Lond) 1949; 110: 36-46.

23 Fisher RB, Gardner MLG. A kinetic approach to the absorption of solutes by isolated perfused small intestine. J Physiol 1974; 241: 211-34.

24 Hanson PJ, Parsons. The utilisation of glucose and production of lactate by in vitro preparations of rat small intestine: effects of vascular perfusion. J Physiol (Lond) 1976; 255: 775-95. 
25 Lesse HJ, Bronk JR. Automated fluorometric analysis of micromolar quantities of ATP, glucose and lactic acid. Anal Biochem 1972; 45: 211-21.

26 Robertson JP, Faulkner A, Vernon RG. Pyruvate dehydrogenase and the regulation of glucose metabolism in ruminant tissues. FEBS Lett 1980; 120: 192-4.

27 Lamers JMJ, Hulsmann WC. The effects of fatty acids on oxidative decarboxylation of pyruvate in rat small intestine. Biochem Biophys Acta 1974; 343: 215-25.

28 Bergeron JJM, Rachubinski R, Searle N, Borts D, Sikstorn R, Posner BI. Polypeptide hormone receptors in vivo: demonstration of insulin binding to adrenal gland and gastrointestinal epithelium by quantitative radio-autography. J Histochem Cytochem 1980; 28: 824-35.

29 Forgue-Lafitte ME, Marescot MR, Chamberlin MC, Rosselin G. Evidence for the presence of insulin binding sites in isolated rat intestinal cells. Diabetologia 1980; 19: 373-48.

30 Sodoyeaux-Goffeaux F, Sodoyez JC, DeVos CJ. Insulin receptors in the gastrointestinal tract of the fetus: quantitative autoradiographic studies. Diabetologia 1985; 28: 45-50.

31 Fernandez-Moreno MD, Senano-Rios M, Prieto JC.
Identification of insulin receptors in epithelial cells from duodenum, jejunum, ileum, caecum, colon and rectum in the rat. Diabete Metabolism (Paris) 1987; 13: 135-9.

32 Gallo-Payet N, Hugon JS. Insulin receptors in isolated adult mouse intestinal cells: Studies in vivo and in organ culture. Endocrinology 1984; 114: 1885-92.

33 Zimmerman TW, Reinprecht JT, Binder HJ. Peptide binding to intestinal epithelium: distinct sites for insulin, EGF and VIP. Peptides 1985; 6: 229-35.

34 Gingerich RL, Gilbert WR, Comens PG, Gavin JR. Identification and characterisation of insulin receptors in basolateral membranes of dog intestinal mucosa. Diabetes 1987; 36: 1124-9.

35 Tejwani GA, Ramaiah A. Properties of phosphofructokinase from the mucosa of rat jejunum and their relation to the lack of a Pasteur effect. Biochem J 1971; 125: $507-14$.

36 Tejwani GA, Kaur J, Ananthanarayanan M, Ramaiah A. Concentrations of various effectors and substrates of phosphofructokinase in the jejunum of rat and their relation to the lack of a Pasteur effect in this tissue. Biochim Biophys Acta 1974; 370: 120-9.

37 Ramaiah A. Pasteur effect and phosphofructokinase. Curr Top Cell Regul 1974; 8: 297-329. 